\title{
The Impact of Applying Artificial Intelligence on the Quality of Decision-Making of Abu Dhabi Police General Headquarters
}

\author{
Nouna Sammari ${ }^{1}$ \& Saif Salem Mohsen Dahnan Almessabi ${ }^{1}$ \\ ${ }^{1}$ Faculty of Leadership \& Management, Universiti Sains Islam Malaysia, Malaysia \\ Correspondence: Saif Salem Mohsen Dahnan Almessabi. E-mail: u0y0.ss@gmail.com
}

Received: October 23, 2020

Accepted: November 2, $2020 \quad$ Online Published: November 30, 2020

doi:10.5539/ass.v16n12p101

URL: https://doi.org/10.5539/ass.v16n12p101

\begin{abstract}
The study aims to examine the impact of applying artificial intelligence on the quality of making decisive security decisions in Abu Dhabi Police General Headquarters. The study uses hypothetical deductive approach to measure impact of applying artificial intelligence on the quality of decision-making. The study uses purposive sample of 100 respondents on staff of Abu Dhabi Police General Headquarters. The results showed that the importance of artificial intelligence was high. This indicates that managerial decision-making is directly or indirectly affected by artificial intelligence within the study sample. This makes the security sectors interested in the developments of artificial intelligence and its outputs and exploits them to save time in making decisions, and achieving quality and acceptance. The results further showed that the level of agreement on administrative decision-making has positive and significant relationship on System Sustainability and Development; Effectiveness of the program used as well as security system of Abu Dhabi Police General Headquarters. Artificial intelligence has become one of the main mechanisms that security sectors rely on in decision-making and represent the most important pillars of development that is indispensable under the changing strong competitions in the world of management, as the information and digital revolution cannot be overlooked and difficult to keep up with at the present time.
\end{abstract}

Keywords: artificial intelligence, decision making time, decision acceptance, decision quality, system sustainability and development, effectiveness of the program used, security system

\section{Introduction}

Artificial intelligence is one of the modern fields that attract the interest of all societies, as well as it witnesses continuous developments. Artificial intelligence is expected to have an important role in the future of humanity, as it is a science within the security work system (Zoheir, 2019). It focuses on designing machines that engage humans in behaviors that are described as intelligent. Today, we use a lot of systems that depend on this science in the fields of economics, medicine, engineering, military, games, and more, it is worth noting that the security services in Western countries rely on intelligence methods. The importance of the information produced through data processing is evident in its use by various departments to reach the strategic goals of the institutions. The management exploits the information that it can collect through the activities of the institution and the environmental effects on it. Thus, senior management can analyze this information and draw conclusions far from guess and use intuition that may occur in case of absence of sufficient information (Shams Al-Din, 2018).

Despite the efforts made by the United Arab Emirates through its governmental institutions, especially the general administration and the leadership of Abu Dhabi Police, in the process of applying artificial intelligence to all its security sectors, the division faces various challenges. The artificial intelligence requires attention to develop systems and applications, and trying to rely on them in making decisions in all matters that require immediate decision-making and using them correctly. However, there are challenges related to the interest of the suitability of the system and the development of the technology related to artificial intelligence necessary for decision-making, as well as the devices and technologies that help in running the security system and making the necessary decisions that saves time, improve quality and acceptability.

The problem has resulted to the following main question: What is the impact of applying artificial intelligence on the quality of decision-making? The main objective is to identify the impact of applying artificial intelligence on the quality of decision- making, this objective divided into several sub-objectives such as to determine the nature of the relationship between decision making and its effects on the System Sustainability and Development of 
Abu Dhabi Police General Headquarters; to examine the relationship between decision making and its effects on the effectiveness of the program used as well as security system at Abu Dhabi Police General Headquarters.

\subsection{Literature Review}

Decision-making process is defined as a process in which a decision is made, information gathered, and alternative decisions evaluated, using the decision- making process and applying its steps is also a way to make more informed decisions by organizing relevant information and identifying alternatives, as decision making is an intellectual process that involves choosing one way of action from many alternatives (Panpatte \& Takale, 2019). Decision-making is also known as a process that occurs daily in homes, schools, political and government organizations, Corporate boards and Executive Offices, Decisions, especially important ones, are made by leaders and managers who are at the top of the organizational hierarchy, and decision making defined as the process by which managers identify organizational problems and attempt to solve them, and the decision-making process involves identifying and choosing between a set of alternatives based on propensity for the better (Alhawamdeh et al., 2019). Decision is defined as the path taken by the decision maker as the best choice among the available options in order to reach his objectives at the level of security sectors. As for the decision making Process Within the current era it is an essential process for carrying out any successful management, as this process is the driver of administrative processes in general, And therefore success of institutions depends on the efficiency of the decisions taken by the management, either the decisions are in the same direction as the main goal of the institutions or hinder the work progress (Yaghi \& Yaghi, 2013).

Artificial intelligence is known as the field in computer science that focuses on creating computer programs that can perform special roles which are characterized by human performance and simulate human behavior that a person considers intelligent behavior (Afifi, 2014). John McCarthy defined artificial intelligence as "the science and engineering of the intelligent machine industry", as Artificial intelligence is a branch of computer science that deals with the study and design of intelligent agents who are aware of their environment and take Procedures that increase the chances of its success (Singh, 2019). Artificial intelligence is defined as directing the computer to perform complex work in a better manner than an individual in the security leadership.

Schmidt (2019) uses the qualitative analytical approach, through interviews and the study revealed that artificial intelligence is currently being implemented at the beginning of the decision-making process, and in fact it is imperative that artificial intelligence must be used during the decision-making process, this is done by reducing uncertainty and bias, and working to increase productivity and efficiency. Moreover, the study has shown that artificial intelligence can be implemented in every step of the decision-making process.

Mélanie \& Dorian (2018) aimed to gain a better understanding of the role of humans and the role of artificial intelligence in the organizational decision-making process, as for the results of the study, it found that the deep understanding of artificial intelligence and its integration in the organizational decision-making process of institutions would contribute to effective decision-making, and the results also included that artificial intelligence is used as a support in decision-making processes instead of independent decision-making. Many organizations have used simpler designs to get the most out of the decision- making process. the results of the study also include an acknowledgment that artificial intelligence is an effective tool for getting out of problems, although human capabilities may be more important in cases of uncertainty and ambiguity, and moreover, artificial intelligence creates new issues for organizations regarding their responsibility and society's acceptance of them in the context of conflict Between machines, morals and laws.

In addition, Al-Shawabkeh \& Kanungo (2017) follows the role of artificial intelligence applications in making administrative decisions and the result revealed that all dimensions of the independent variable for artificial intelligence applications (expert systems, suitability for the system, training and development, the smart program used and the security system) were high, and that all dimensions of the dependent variable, administrative decision-making at the time of decision- making, decision acceptance and decision quality were also high. The study also showed the existence of a statistically significant effect of the dimensions of the independent variable (the suitability of the system, the training and development process, the effectiveness of the smart program used and the security system) on the dimensions of the dependent variable the administrative decision-making (decision-making time, the quality of the decision and the acceptance of the decision).

Moreover, Saleh (2009) aimed to follow the impact of applying artificial intelligence and emotional intelligence on the quality of decision-making. The results of the study include a statistically significant relationship between using artificial intelligence methods and the quality of administrative decision-making, as this relationship was explained by the value of R-Square, which equals $0.5 \%$, and it became clear that there is a statistically significant relationship between using emotional intelligence methods and the quality of managerial decisions. 
The results also showed that there is a statistically significant relationship between motives as it is one application of emotional intelligence and the quality of decision-making. Accordingly, it became clear that there is a statistically significant relationship between the ability of the system and the quality of decision-making, by conducting the Paired Sample T- Test, the results showed that there is a statistically significant relationship between the type of smart program used in artificial intelligence methods and the quality of decision-making.

The great progress in the field of artificial intelligence and the exchange of experiences in this field between individuals and specialists resulted in the intensification of competition between different institutions to develop systems even before appearing of the term of globalization, Advanced systems have updated advanced systems significantly through artificial intelligence to the extent that they do some of the work that humans do, but better (Arnos, 2018). Accordingly, the researcher will address the impact of applying Artificial Intelligence on the quality of decision making. However, from the prior research findings, it became clear that this study is in line with the current research in dealing with the effect of artificial intelligence on decision-making and the extent of its use in all fields, as previous studies indicated the importance of identifying the impact of artificial intelligence on decision-making. Therefore, the researcher believes from the reality of his work in the Abu Dhabi Police General Headquarters and his interest in improving performance in its human resources departments that it is necessary to study these factors and apply it to Abu Dhabi Police General Headquarters.

\subsection{Research Framework}

Figure 1 shows the conceptual framework of the study. The study is based on testing therelationship between the following: Artificial Intelligence (Independent Variable): (System Suitability and Development - Effectiveness of the smart program used - Security System) and Administrative Decision-Making (Dependent Variable): (Decision- Making Time - Decision Quality - Decision Acceptance).

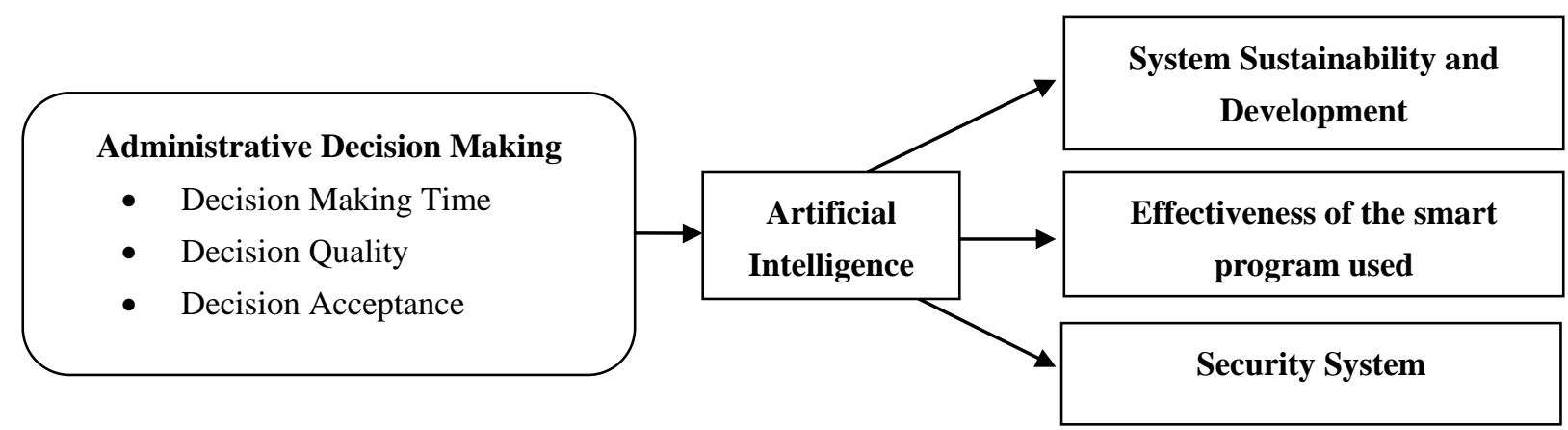

Figure 1. Framework on Decision Making and Artificial Intelligence

\subsection{Hypotheses of the Study}

H1: There was no statistically significant effect at the significance level of Artificial Intelligence and its dimensions (System suitability and development - effectiveness of the smart program used - security system) on administrative decision-making and its dimensions (decision-making time - decision-making quality - decision acceptance).

This main hypothesis divided into the following sub hypothesis:

- H1a: There is no statistically significant effect at the significance level of artificial intelligence on the decision time at Abu Dhabi Police General Headquarters.

- H1b: There is no statistically significant effect at the significance level of artificial intelligence on decisionmaking quality at Abu Dhabi Police General Headquarters.

- H1c: There is no statistically significant effect at the significance level of artificial intelligence on decision acceptance at Abu Dhabi Police General Headquarters.

\section{Methodology}

The researcher used descriptive analytical method in his study, as this method is a broad and flexible umbrella that may include a number of curricula and sub-methods such as social surveys, case studies, developmental, and field studies, and others. The descriptive and analytical approach is based on identifying the characteristics of the phenomenon and describing its nature and the quality of the relationship between its variables, causes and 
trends, and other aspects that revolve around the ways of the study problem, and identifying its reality of the existing situation in the study community, determining the conditions and relationships that exist between variables, artificial intelligence as an independent variable and Decision making as a dependent variable. The analytical descriptive method collects descriptive data about the phenomenon to analyze, link and explain this data, classify and measure it and extract conclusions from it.

The researcher used the Statistical Package for the Social Sciences (SPSS) program, and nonparametric statistical tests were used. Five-point ordinal likert scale was used. Cronbach's Alpha was used to test validity and reliability of data. Percentages, arithmetic averages, and standard deviations were used to test the frequency of variables. The study uses the simple correlation coefficient to determine the strength and nature of the relationship between variables and simple linear regression in measuring the significant effect of the independent variable on the dependent variable.

The study population consists of staff working in administrative positions within the Abu Dhabi Police General Headquarters in the following department (Mussafah Police Station and its various branches connected to it Operations management and its branches, departments and connected centers - Abu Dhabi Drivers and Vehicles Licensing management - Department of motor vehicles, patrol and its branches and department) who occupy positions (general managers - deputies of departments - director of branches and his deputies - Director of departments and his deputies - deputy director of the sector - head of department in the sector - workers). Abu Dhabi Police employs 12,500 frontline staff. There is a total staff of 36,000 including civil defense, ambulance and fire services and border security. Under the Commander General of Abu Dhabi Police there are five departments which report directly. The researcher applies the purposive sample to the study population, which consists of (120) managers, deputies, heads of departments and workers, and (20) forms were screened out due to their incomplete data, and (100) forms were used for the statistical analysis process.

\section{Analysis and Results}

\subsection{Validity and Reliability}

It was found from all the data in table 1 that all the basic research variables have an acceptable stability rate, where the Cronbach alpha rate for the study variables ranges between $(0.701-0.843)$. This indicates the accuracy of the data and their reliability, and the validity factor shows that the scale can be measures what was put to measure, where the value of the validity factor for all dimensions ranged from $0.837-0.918$.

Table 1. Cronbach Alpha Coefficient and Validity

\begin{tabular}{ccc}
\hline Dimensions & Cronbach Alpha Coefficient & Validity \\
\hline System suitability and development & 0.843 & 0.918 \\
Effectiveness of the program used & 0.706 & 0.840 \\
Security system & 0.701 & 0.837 \\
Time to make a decision & 0.833 & 0.913 \\
Decision quality & 0.824 & 0.908 \\
Decision acceptance & 0.760 & 0.872 \\
General index & 0.778 & 0.882 \\
\hline
\end{tabular}

\subsection{Descriptive Analysis}

Table 2. Overall Arithmetic Mean and Standard Deviation

\begin{tabular}{clccc}
\hline & \multicolumn{2}{c}{ Variables } & Average & Standard Deviation \\
\hline Artificial Intelligence & 1 & System suitability and development & 3.370 & 1.126 \\
& 2 & Effectiveness of the program used & 3.333 & 1.007 \\
\multirow{2}{*}{ Decision Making } & 3 & Security system & 3.120 & 1.304 \\
& 1 & Time to make a decision & 3.09 & 1.344 \\
& 2 & Quality of decision & 3.783 & 1.097 \\
& 3 & Acceptance of the decision & 3.922 & 1.155 \\
\hline
\end{tabular}

It is evident from the Table 2 indicators that the general arithmetic means of the variable (appropriateness of the system and development) reached $(3,370)$ with a standard deviation of $(1,126)$ with an overall agreement of (67.4\%). The general arithmetic mean of the variable (the effectiveness of the program used) reached (3.333) 
with a standard deviation of (1.007) with an overall agreement of (66.7\%). The above mentioned indicators shows that the general arithmetic mean of the (security system) variable reached (3.120) with a standard deviation of (1.304) with an overall agreement of (62.4\%).

By analyzing the results of the dependent variable making administrative decisions, this axis included three dimensions, namely (decision-making time), represented by three paragraphs (decision quality), represented by six paragraphs (acceptance of the decision), and represented by four paragraphs, the results of them were as shown in tables (5), (6) and (7), The following is a presentation of each of them: The above mentioned indicators shows that the general arithmetic mean of the variable (decision making time) reached (3.09) with a standard deviation of $(1,344)$ and an overall agreement of $(61.8 \%)$. The above mentioned indicators shows that the general arithmetic mean of the variable of (decision quality) reached (3.783) with a standard deviation of (1.097) and with an overall agreement of $(75.7 \%)$. The above mentioned indicators shows that the general arithmetic mean of the variable (acceptance of the decision) reached (3.922) with a standard deviation of $(1,155)$ with an overall agreement of $(78.4 \%)$

\subsection{Results}

Table 3 shows that the null hypothesis on artificial intelligence is not supported. The relationship between the independent variable "artificial intelligence" and the dependent variable "administrative decision-making" shows direct relationship with a positive value of (0.507) and significant relationship less than (0.05), which means that the relationship is statistically significance, the value of the determination coefficient (R2) was (0.257), which means that the independent variable affects the dependent variable with $(25.7 \%)$ and thus the null hypothesis is rejected.

Table 3. Simple Regression Analysis

\begin{tabular}{ccccc}
\hline Variables & $\begin{array}{c}\text { Correlation } \\
\text { Coefficient }\end{array}$ & R-Square & $\begin{array}{c}\text { The calculated (F) } \\
\text { Value }\end{array}$ & $\begin{array}{c}\text { Significance } \\
\text { Level }\end{array}$ \\
\hline Artificial intelligence & 0.507 & 0.257 & 16.764 & 0.000 \\
System suitability and dev. & 0.585 & 0.342 & 25.196 & 0.000 \\
Effectiveness of the program used & 0.463 & 0.215 & 13.265 & 0.000 \\
Security system & 0.512 & 0.263 & 17.269 & 0.000 \\
\hline
\end{tabular}

Table 3 shows that the null sub-hypothesis on System suitability and development is not supported. The relationship between the independent variable "artificial intelligence" and the dependent variable "administrative decision-making" shows direct relationship with a positive value of (0.585) and significant relationship less than (0.05), which means that the relationship is statistically significance, the value of the determination coefficient (R2) was (0.342), which means that the independent variable affects the dependent variable with (34.2\%) and thus the null hypothesis is rejected.

Table 3 shows that the null sub-hypothesis on Effectiveness of the program used is not supported. The relationship between the independent variable "Effectiveness of the program used" and the dependent variable "administrative decision-making" shows direct relationship with a positive value of (0.463) and significant relationship less than (0.05), which means that the relationship is statistically significance, the value of the determination coefficient (R2) was (0.215), which means that the independent variable affects the dependent variable with $(21.5 \%)$ and thus the null hypothesis is rejected.

Table 3 shows that the null sub-hypothesis on Security system is not supported. The relationship between the independent variable "Security system" and the dependent variable "administrative decision-making" shows direct relationship with a positive value of (0.512) and significant relationship less than (0.05), which means that the relationship is statistically significance, the value of the determination coefficient (R2) was (0.263), which means that the independent variable affects the dependent variable with (26.3\%) and thus the null hypothesis is rejected.

\section{Discussion and Conclusion}

The importance of decision-making is reflected through the administrative and organizational work and the responsibilities that the manager bears to reach the appropriate decisions, the decision- making process is an organizational process, Accordingly, the manager alone cannot held full responsibility for the process, but rather everyone participates with him in the stages of the decision-making process. The study is concerned with identifying the importance of the decision-making process, and the study is also concerned with discussing the 
factors that help managers and institutions in general in the decision-making processes through using artificial intelligence in the security sector in the United Arab Emirates.

\subsection{Findings and Recommendations}

In this research paper, the study aimed at identifying the impact of artificial intelligence on administrative decision-making, the results showed that the importance of artificial intelligence in the study community was high from the point of view of the study sample, and this indicates that administrative decision- making is directly or indirectly affected by artificial intelligence within the study sample, and that makes the security sectors interested in the developments of artificial intelligence and its outputs and exploits them in the development and the necessity of Saving time when making decisions in the field of security and security services, and through that, the goals pursued by the various security sectors can be achieved, due to the fact that the interest in artificial intelligence helps in achieving the maximum use of the available resources, which is reflected in the security sector as a whole, and increases The service, economic and social return for those sectors, which in turn makes the decision- making policies that are applied are more effective at the operational level. Based on the findings obtained, the researcher recommends the following:

1. The need to raise the efficiency and effectiveness of the system used in decision-making in the General Headquarters with the necessity to provide the time necessary for decision-making, The extent to which the system provides in the human resources management of the Abu Dhabi Police General Headquarters must be reconsidered to support timely decision-making to avoid problems that exist in the information Provided by the system.

2. The level of interest in the effectiveness of using artificial intelligence, led by Abu Dhabi Police, should be raised in all its administrative aspects and not using artificial intelligence just for its use, there is no value for technology without realizing its effectiveness and benefiting from this effectiveness.

3. Personnel in the General Headquarters must be trained to keep pace with modern technological developments to suit the new technical challenges and to rely on them in making administrative decisions and implementing them to achieve quality and acceptance.

4. Experts must be available to develop the information system used continuously to avoid problems that may occur during use, and the possibility of making the necessary adjustments according to the conditions and requirements of use.

5. The necessity of providing the Human Resources management at the General Headquarters with electronic services that are appropriate to the needs of employees, and the administration must develop them from time to time in order to fully play its role equally, for using in dealing with administrative decisions in the implementation and follow-up stages.

6. Activating the use of technology and artificial intelligence in the decision- making process to ensure speed, accuracy, and follow-up and review when needed.

7. Establishing an evaluation system to verify the extent to which the decisions taken have achieved their objectives under using artificial intelligence as an aid in implementing and applying security decisions.

8. The results obtained from the implementation of decisions must be compatible with the security system so that neither of them conflict, and thus the security system will lose its effectiveness.

9. The necessity of investigating accuracy in the surveys carried out by the Human Resources Department at Abu Dhabi Police to determine its administrative needs, and to improve performance in decision-making so that it can know its strengths and weaknesses points, the areas of danger and opportunities therein, and how to deal with each of them with full awareness. Attention to the objectivity of the decisions taken at Abu Dhabi Police General Headquarters, because that raises the level of confidence and effectiveness, directly and indirectly.

\subsection{Conclusion}

This result showed that the level of agreement on administrative decision- making in the study sample was high, from the viewpoint of the study sample, as it demonstrates the importance of the administrative decision-making component in the Abu Dhabi Police General Headquarters, and how it leads to quality and acceptance in order to help achieve public and private benefit, directly and indirectly within the study community, and how adherence to the rules required by decision-making achieves the desired goal of the security and administrative process, which is sustainability, achieving security, development and serving the largest number of beneficiaries in the first place. 


\section{References}

Afifi, J. A. (2014). Artificial Intelligence and Expert Systems. Amjad Publishing and Distribution, Amman.

Alhawamdeh, H. M., Mohammad, A., \& Alsmairat, K. (2019). Strategic Decision Making and Organization Performance: A Literature Review. International Review of Management and Marketing, 9(4), 95. https://doi.org/10.32479/irmm.8161

Al-Shawabkeh, A., \& Kanungo, R. (2017). Credit risk estimate using internal explicit knowledge. Investment Management and Financial Innovations, 14(1), 55-66. https://doi.org/10.21511/imfi.14(1).2017.06

Arnos, B. (2007). Artificial Intelligence. Dar Al Sahab Publishing and Distribution, Cairo.

Mélanie, C., \& Dorian, C. (2018). The Roles of Artificial Intelligence and Humans in Decision Making: Towards Augmented Humans? Department of Business Administration. Master's Program in Business Development and Internationalisation. Master'sThesis in Business Administration I. 15 Credits.

Panpatte, S., \& Takale, V. D. (2019). To Study the Decision Making Process in an Organization for its Effectiveness. The International Journal of Business Management and Technology, 3(1).

Saleh, F. A. (2009). The Effect of Applying and Using the Methods of Artificial Intelligence and Emotional Intelligence on Decision Making. Unpublished M. A. Middle East University, Amman, Jordan

Schmidt, C. (2019). The Impact of Artificial Intelligence on Decision-Making in Venture Capital Firms. Dissertation submitted in partial fulfillment of requirements for the MSc in International Management, at the Universidade Católica Portuguesa.

Shams Al Din, A. H. (2018). Government by Judiciary in Islam: Islamic Theory of Government and Mal/Practice of Muslim Governments (Turkey, Saudi Arabia, Egypt and Morocco). California Western International Law Journal, 48(2), Article 5.

Singh, G., Ajitanshu, M., \& Dheeraj, S. (2019). An Overview of Artificial Intelligence. Bit Journal of Sciences and Technology, 2(1), 20.

Yaghi, A., \& Yaghi, I. (2013). Human resource diversity in the United Arab Emirates: empirical study. Education, Business and Society: Contemporary Middle Eastern Issues, 6(1), 15-30. https://doi.org/10.1108/17537981311314682

Zoheir, S. (2019). Zoheir Sabeur's Artificial Intelligence and Knowledge Extraction Lab. Bournemouth University

\section{Copyrights}

Copyright for this article is retained by the author(s), with first publication rights granted to the journal.

This is an open-access article distributed under the terms and conditions of the Creative Commons Attribution license (http://creativecommons.org/licenses/by/4.0/). 